\title{
ИММУНОГИСТОХИМИЧЕСКАЯ ХАРАКТЕРИСТИКА МОРФОЛОГИЧЕСКИХ ВАРИАНТОВ АДРЕНОКОРТИКАЛЬНОГО РАКА
}

Селиванова Л.С.

\author{
ФГБУ «НМИЦ эндокринологии» Минздрава России, Москва
}

Адренокортикальный рак (АКР) является вторым после анапластической карциномы щитовидной железы злокачественным эндокринным новообразованием, вызывающим наибольшую летальность. Результаты исследований свидетельствуют, что АКР характеризуется выраженной морфологической и иммуногистохимической гетерогенностью. Однако в настоящее время не существует четких морфологических критериев для выделения вариантов АКР и не до конца изучено их клиническое и прогностическое значение.

ЦЕЛЬ: проанализировать 75 случаев АКР во взрослой популяции с диагностикой морфологических вариантов и акцентом на их гистологические и иммуногистохимические характеристики.

МАТЕРИАЛЫ И МЕТОДЫ: бЫЛо ВЫПолнено гИстологическое и иммуногистохимическое исследование операционного материала 75 пациентов, получивших лечение в НМИЦ эндокринологии Минздрава России или в других лечебных учреждениях, а также анализ доступных клинических данных.

РЕЗУЛЬтАТЫ: были охарактеризованы основные гистологические варианты АКР с описанием паттернов роста. Классический подтип АКР выявлен у 51 (68\%), онкоцитарный - у 15 (20\%), миксоидный у 9 (12\%) пациентов. Функциональная активность опухолей наблюдалась в 18 (43\%), 4 (33\%) и 2 (22\%) случаях классического, онкоцитарного и миксоидного вариантов соответственно. Экспрессия SF-1 наблюдалась во всех исследуемых случаях АКР в независимости от его морфологического подтипа; выраженность реактивности Melan A и Inhibin А отличалась в зависимости от выделяемых вариантов АКР. Экспрессия АМА характеризовалась сильным диффузным иммуногистохимическим окрашиванием эозинофильной гранулярной цитоплазмы только при онкоцитарном варианте. Индекс Кі-67 в классическом варианте АКР находился на уровне 20\%, в онкоцитарном варианте - 10\%, при миксоидном варианте 15\%. Экспрессия р53 была выявлена у 14 (18,6\%) пациентов. Выделение морфологических вариантов АКР и использование прогностически значимых иммуногистохимических маркеров позволит усовершенствовать диагностику АКР и тактику ведения пациентов.

КЛЮЧЕВЫЕ СЛОВА: адренокортикальный рак, АКР, классический, онкоцитарный, миксоидный, гетерогенность. 